\title{
The Feasibility Analysis of the Application of PAD Class in Preparatory College Computer Teaching
}

\author{
Qun Xia \\ Nanchang Institute of Science \&Technology, Nanchang Jiangxi 330108, China
}

Keywords: PAD class; preppie; teaching model

\begin{abstract}
In recent years, the education sector has made innovations and improvements to the education model. The scholar had put forward a new teaching model called PAD class education model, this model combines the teaching model with the discussion mode, he advocated that the time of teachers teach and students discuss should be bisected. This article based on the course "computer", combined with years of experience and achievements in teaching, bring PAD class education model to the door of the classroom teaching, improve the students' learning autonomy and initiative, to enhance the effectiveness of student learning.

At present, although the educational circles have been calling for the new curriculum reform, most teachers still use the traditional rigid teaching mode in the actual teaching. This kind of teaching mode can not only arouse the enthusiasm of the students, it also can not make the students understand and use the knowledge. How to jump out of the traditional teaching mode to meet the teaching requirements of the new curriculum reform is an important topic in computer teaching.
\end{abstract}

\section{Introduction}

PAD Class is not overthrow the negative on the traditional teaching, but the integration of the two reasonable, give full play to their strengths, and compensate for their shortcomings, is the core concept of sub class, distribution put half of the class time for teachers to teach, the other half of the time allocated to learn students to discuss the form of interactive learning, classroom on the teaching process is divided into about presentation, assimilation to discuss and internalize the Discussion three time are separate but interconnected in the content section, similar to the traditional classroom, classroom emphasizes on teaching before, teachers teach students first.

After learning. A similar discussion on the classroom, classroom emphasizes students and teacher-student interaction, encourage autonomous learning, on the surface, the classroom is a teaching type and discussion teaching mode, in fact, the key lies in the innovation of its teaching and discussion time staggered, let the students in the class have time to arrange their own study, absorption to internalize the personalized, independent learning and thinking on the classroom very stressed students, this is not only conducive to the cultivation of students' autonomous learning ability, but also to respect students' individual differences, because as a psychological process of one of the most important characteristics of different students internalization of knowledge is internalized speed and internalization methods are different. Students should take their own pace to complete the internalization process. In the course of the study, the students can understand the time and space of the class, and they also provide abundant content for the group discussion in the next class. It can be said that teaching, internalization of absorption and discussion is the three interlocking, layer by layer, each of the different tasks. 
In addition, in the examination method, PAD Class emphasizes the process of evaluation, the performance and the work of the students in the classroom has been included in the scope of examination, students can determine the course of investment according to the learning goals, needs and interests of the individual.

In 2013, the total scale of the college students in the country reached about thirty million, which achieved the transition from elite education to mass education at an unprecedented speed. Preparatory students have soared in the past two years, however, there is a large scale behind the problem of reducing the quality of education. According to the characteristics and problems of the preparatory study, this paper attempts to make a teaching model of "PAD Class."

\section{Problems existing in preparatory course of computer basic courses}

With the current mode of higher education transformation from elite education to mass education, leap development of higher education in our country, but at the school, as we students, only from the perspective of university classroom learning atmosphere, absence rate is high, the students play mobile phone, read novels, and extracurricular activities, even the phenomenon of sleep is relatively common, the current problems in the teaching of teaching goals too high, not suitable for the teaching of minority preparatory students. Sometimes the objective resulted in small class students would listen, hands-on play games, learning completely in a passive state, in addition, the university classroom general class for a very long time, it is difficult for students to keep long time attention to teaching, to a certain extent, the unfavorable situation limits our matriculation students computer course teaching. Cause the above situation, the main reasons are the following aspects:

Learning interest is not high. Although the development of information technology changes, many students do not understand the information, the importance of the basic operation of the computer experience is not profound.

The content of learning is too difficult or too simple. A small number of students have participated in the examination because of the college entrance examination, computer based courses have a certain understanding and mastery. Too simple, can not arouse his enthusiasm and participation in class. And some students have never been exposed to the computer, the computer course has a fear. Lead to learning participation is not high.

Monotonous teaching methods. Computer basic courses, most of them are practice, so in the classroom, in the classroom, most of the teachers still use the operation method, the teacher explained, the students practice mode. Many students feel that is the operation, not too much emotional communication. Therefore, students are a little tired.

\section{The core idea and implementation process of the teaching mode of PAD Class}

Among the many methods of teaching reform, the reform of traditional teaching is to adopt the discussion teaching method. Many famous universities in foreign countries regard this method as the second teaching method after classroom teaching. More and more attention has been paid to the guidance of students' participation in the learning process, and the process of interaction between teachers and students should be strengthened to improve teaching effectiveness. Based on this idea, in 2014, Professor Zhang Xuexin from Fudan University put forward a new classroom teaching model, called "PAD Class". The core idea of the model is to assign half of the class time to teachers for teaching, and the other half for students to discuss the form of interactive learning. The advantages of the model is that, a discussion between two processes to give students a week to read, by reading textbooks, course assignments, literature reading and other ways to help students to 
understand and digest the teacher lectures, the students have the ability, with the issue in the next classroom discussion, to avoid the existing discussion of classroom teaching form, speak generally small foot. On the basis of classroom discussion, the teacher carries on the necessary summary to the curriculum content, helps the student to understand the curriculum content more deeply, let them grasp the knowledge to be more organized and structured.

\section{Feasibility analysis of PAD Class teaching mode of computer basic course for preparatory students}

At present, there are more than 100 colleges and universities in the country to participate in the curriculum reform experiment of "sub class", involving psychology, foreign language, philosophy, political science, optics and other subjects. Teaching methods and experimental design of psychology in Fudan University and the teaching experiment table of the oral English course of University of Shanghai for Science and Technology. Compared with the traditional teaching method, the teaching mode of "PAD Class" has achieved very good results. From the specific practice, the "PAD Class" teaching model is applied to the teaching of undergraduate and graduate courses, and has achieved good results. The reform of the process is an economic, practical, worthy of promotion of the curriculum model.

The rationality of dividing class in college computer basic class. Reasonable arrangement of time. "The superiority on the classroom teaching mode is discussed, the two process ask give students a week in teaching, by reading textbooks, course assignments, literature reading and other ways to help students to understand and digest the teacher lectures, the students have the ability, with the issue in the next classroom the discussion, to avoid the lack of classroom teaching have been discussed the form. On the basis of classroom discussion, the teacher carries on the necessary summary to the curriculum content, helps the student to understand the curriculum content more deeply, let them grasp the knowledge to be more organized and structured. Based on the arrangement of the basic courses for the students of the preparatory course for the students in our university, once a week, from time to time, it is very suitable for the course.

In the teaching concept, the "teacher centered" model is transformed into a "teacher and student" common center model, to play the initiative of students. Basic computer courses in theory are teachers' teaching, emphasize teacher centered mode, through the reform of teaching mode, can be part of the theory of knowledge and knowledge need to expand the connection link of teaching to the students, by the students responsible for a subject teaching, including lecture content arrangement and organization, teaching courseware work, strengthen the leading role of students in teaching.

Teaching methods to improve student participation. The computer is based on the practice of curriculum, based on the result, through a week of preparation time, can let students teach and practice content, enhance the participation of students, let the students into the classroom, teacher identity, improve their learning enthusiasm and initiative. Optimize the evaluation system, establish a scientific and comprehensive evaluation system. It is helpful to establish a scientific and reasonable evaluation system for students. Because using the bisection class form, we can have more scores in quantitative index score, such as classroom lectures participation, quality lectures, team and group cooperation in the performance, and the usual engagement party.

The problems that may be faced in the application of computer to the basic class.

How to effectively arrange and monitor the students' homework. Ask the teaching content and the content of teachers to organize the natural transition, teachers how to make accurate comments in student activities, teachers of students in the teaching process, the rich are highly involved $\mathrm{Bu}$ can 
effective classroom management, very challenging for most of the young teachers, but also can bring the necessary guarantee for reform of the classroom teaching efficiency .

The problems that may be faced in the application of computer to the basic class

How to effectively arrange and monitor the students' homework, ask the teaching content and the content of teachers in how to organize students to natural transition, teachers how to appropriate accurate comments in student activities, a high degree of participation of teachers in students teaching, enrich the degree can effective classroom management, very challenging for most of the young teachers, but also can bring the necessary guarantee to reform classroom teaching efficiency.

The problems that may be faced in the application of computer to the basic class.

How to effectively arrange and monitor the students' homework, ask the teaching content and the content of teachers in how to organize students to natural transition, teachers how to appropriate accurate comments in student activities, a high degree of participation of teachers in students teaching, enrich the degree can effective classroom management, very challenging for most of the young teachers, but also can bring the necessary guarantee to reform classroom teaching efficiency. The starting point of the classroom is to mobilize the enthusiasm of students, improve the participation of the classroom. In this sense, it has universal applicability, of course, we can ignore its problems. On the whole, we can try to be in the basic computer class or worth exploring. As a new teaching mode, the teaching of the class has promoted the interaction between "teaching" and "learning", which has manifested the main body status of the students, mobilized the initiative and creativity of the students, and improved the teaching effect. The concept of education in accordance with the requirements of the new curriculum reform, the importance of improving the effectiveness of computer teaching promoting effect. However, the teaching mode is still in the initial stage of exploration, and the practice and innovation need to be mature a teacher's teaching of knowledge is complete and detailed, and the students' understanding of knowledge will be limited and lack of room for improvement. The teachers on classroom only on the content framework, basic concepts and difficult to explain, after leaving the students enough time to internalize the content learned in a lesson, teachers give guidance and evaluation can be certain. Independent arrangements for learning, clear the content of classroom discussions, deepen the understanding of knowledge and mastery, teaching effect is bound to be improved. Under this kind of new teaching mode, the teacher uses the guided teaching, the key concept is to guide the students, which is beneficial to the cultivation of students' independent thinking and self-learning habits and perfect.

\section{Conclusion}

As a new teaching mode, the teaching of the class has promoted the interaction between "teaching" and "learning", which has manifested the main body status of the students, mobilized the initiative and creativity of the students, and improved the teaching effect. The educational idea of the classroom is in line with the requirements of the new curriculum reform, and it is important to improve the teaching effect. However, the teaching mode is still in the initial stage of exploration, and the practice and innovation need to be mature and perfect.

\section{References}

[1] Yang Yuemei. Deep integration of economic mathematics and modern information technology in financial institutions [J]. education exploration, 2013, (8): 40-41

[2] Wang Yu, Ma Fangfang, Chen Ling et al. Development economics "flipped classroom teaching mode of exploration and application of [J]. business economics, 2016, (5): 161-162 
[3] Li Nan. A study on the application of task based language teaching in the teaching of economic application: a case study of Hubei Polytechnic University science and technology [J]. 2015,28 (20): 83-84 